\title{
Xanthogranulomatous pyelonephritis presenting with unilateral renal vein thrombosis
}

\author{
T. A. AkINTEWE* \\ M.B., Ch.B., M.R.C.P.
}

S. Dealler

M.B., Ch.B.

\author{
A. W. HutCHEON \\ M.D., M.R.C.P.
}

* Aberdeen Group of Hospitals, and Woodend General Hospital, Aberdeen

\begin{abstract}
Summary
Haematuria in an elderly patient is a common urological complaint. A patient is described in whom xanthogranulomatous pyelonephritis presented as unilateral renal vein thrombosis. So far as the author is aware, this is the first report of such an association.
\end{abstract}

\section{Case report}

A 60-year-old female was admitted with frank haematuria of sudden onset. Eight weeks before admission she had experienced a dull right flank pain, radiating to the groin. There were no other urinary symptoms. The only previous illness was of 3 transient cerebral ischaemic attacks 4 years earlier, for which she was placed on long-term warfarin. This had been well controlled by monthly prothrombin times.

Clinical examination was normal apart from a large tender right kidney. She was normotensive.

Investigations revealed heavily blood-stained urine, microscopy showing abundant red cells with numerous granular casts. Urine culture was persistently sterile. Intravenous pyelogram showed nephrocalcinosis and a large, non-functioning right kidney (Fig. 1). Because of this, a right retrograde pyelogram was performed as an emergency, but no ureteric obstruction was demonstrated. This was followed by venography, which showed complete occlusion of the right renal vein one $\mathrm{cm}$ from its origin. Renal arteriography showed complete disruption of the normal vascular pattern, with extensive ill-defined avascular areas (Fig. 2). There was no evidence of malignant circulation.

Other investigations showed a high erythrocyte sedimentation rate with a well developed hypochromic, microcytic anaemia, her $\mathbf{H b}$ being $\mathbf{9 \cdot 2} \mathrm{g} / \mathrm{dl}$. She had a mild neutrophilia and thrombocytosis of $786 \times 10^{9} / 1$. Bone marrow showed abundant stainable iron confirming the presence of a secondary anaemia, and in addition suggesting that the thrombocytosis was secondary to acute blood loss. There was a mild

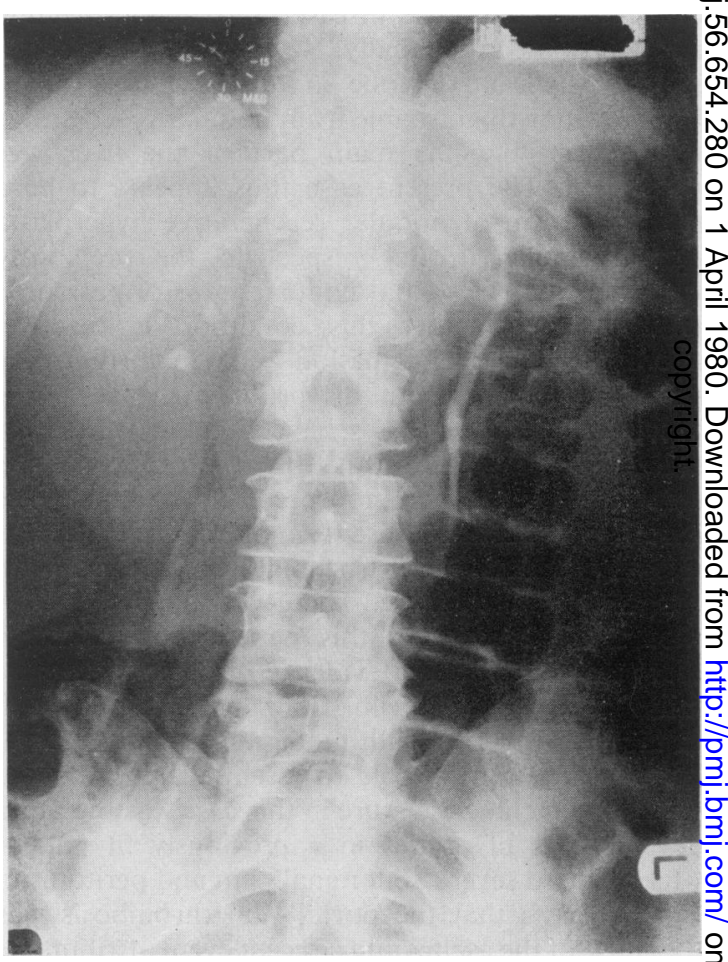

FIG. 1. Intravenous pyelogram showing nephrocalcinosis and a large non-functioning right kidney.

upset in hepatic function, her alkaline phosphatase being $160 \mathrm{u} . / 1$, and $\gamma$-glutamyl transferase $95 \mathrm{u} . / 1$ 요 Blood urea, serum creatinine and creatinine clear ${ }^{\mathrm{N}}$ ance were all within normal limits. Twenty-four hre urinary protein was less than $0.5 \mathrm{~g}$. Urine calciunte was normal. Antinuclear factor was negative.

\section{Comment}

This patient presented with several problems in diagnosis and management. She developed righ? 
renal vein thrombosis while being treated adequately with warfarin and was shown by pyelography also to have xanthogranulomatous pyelonephritis. This is thought to be a chronic inflammatory disease of unknown aetiology, affecting only one kidney and found in association with renal calculi and infection, particularly with Proteus, Escherichia coli and Pseudomonas. Xanthogranulomatous pyelonephritis can be mistaken for renal carcinoma both macroscopically and microscopically. Pre-operative diagnosis of the disease is therefore important.

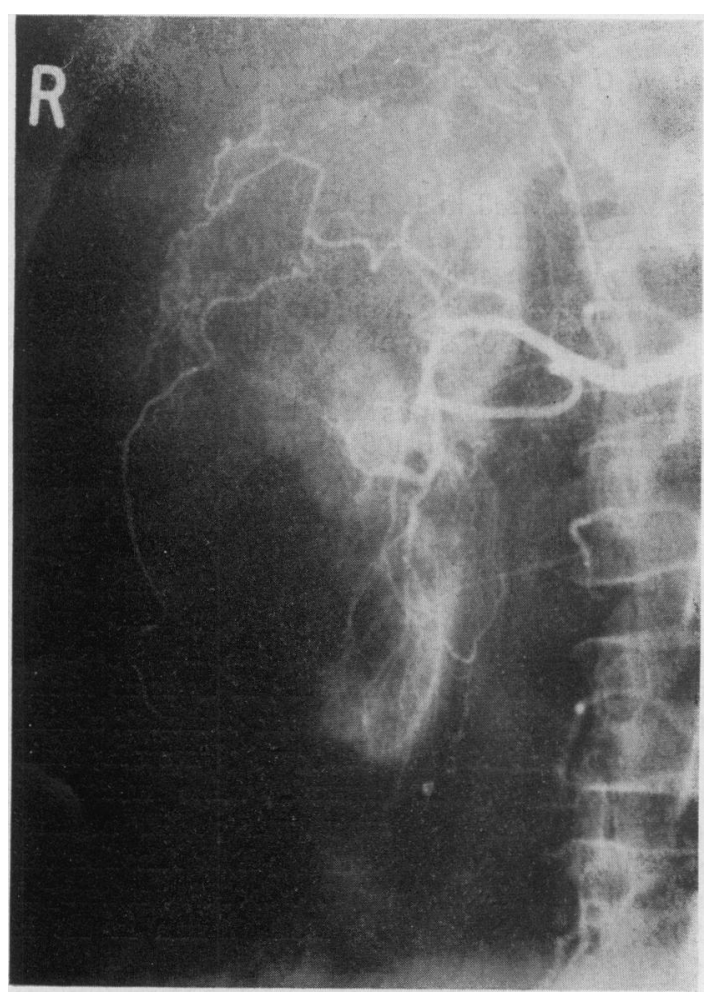

Fig. 2. Renal arteriogram showing the features of xanthogranulomatous pyelonephritis.
Friedenberg and Spjut (1963) described a typical pyelographic appearance which showed an enlarged non-functioning kidney which was obstructed at the uretero-pelvic junction, most often by a large calculus. Renal arteriogram confirms the diagnosis showing irregular small arteries and/or a capillary blush in the kidney containing xanthogranulomatous granulation tissue (Noyes and Palubinskas, 1969). Microscopy shows a tumefactive type of pyelonephritis with large numbers of macrophages filled with a foamy lipid-laden type of cytoplasmic inclusion (Warren and Alperin, 1974). The condition is rare, and Malek et al. (1972) found only 18 cases out of 3000 kidneys with chronic pyelonephritis studied in the Mayo Clinic over a 53-year period.

There is little guidance as to further management. The renal vein thrombosis occurred while the patient was on well controlled anticoagulants. Previous reports recommend nephrectomy (Noyes and Palubinskas, 1969; Malek et al., 1972) either because of the pre-operative diagnosis of renal carcinoma or for intractable renal infection. This patient quickly became asymptomatic and has so far remained so. Surgical advice at present is against nephrectomy because of the patient's general wellbeing, and the technical difficulties associated with the increased vascularity in this region.

\section{Acknowledgements}

We are grateful to Dr G. Mahaffy for performing the arteriograms, Mr W. H. H. Garvie for his advice on this patient, and Miss Roberta Allardyce for her secretarial assistance.

\section{References}

FriedenberG, M.J. \& SpJut, H.J. (1963) Xanthogranulomatous pyelonephritis. American Journal of Roentgenology, 90, 97.

MaleK, R.S., Greene, L.F., DeWeerd, J.H. \& Farrow, G.M. (1972) Xanthogranulomatous pyelonephritis. British Journal of Urology, 44, 296.

Noyes, W.E. \& Palubinskas, A.J. (1969) Xanthogranulomatous pyelonephritis. Journal of Urology, 101, 132.

WARREN, M.M. \& AlPERIN, J.B. (1974) Xanthogranulomatous pyelonephritis and agglutination of erythrocytes. Urology, 111, 67. 